\title{
Exploring the expectations of preceptors in graduate nurse transition; a qualitative interpretative study
}

\begin{abstract}
Preceptors provide fundamental support for the graduate registered nurse, acting as both teacher and role model with an aim to transition the graduate to becoming an independent practitioner. The purpose of this study was to investigate the expectations of the preceptor role from the preceptor's perspective. An interpretative phenomenological approach was used to explore the experience of being a preceptor with seven nurses working in acute clinical areas.

Three themes emerged from the thematic analysis; balancing the preceptor role, exploring past experiences reveals current expectations and developing relationships. Participants had distinctive views on their role during the graduates' transition period, which were influenced by personal experience. Preceptors discussed their role including; education and support and the influence of the connection with the graduate nurse. The participants reflected on their own experiences and how this challenged their role expectations. Graduate characteristics were also highlighted to influence the balance of support. Overall the role of the preceptor was a complex role of balancing support and guidance while aiming to achieve professional development. The development of communication workshops and relationship building programs may be useful in addressing the multiple influencing elements of this relationship.
\end{abstract}

Key words: preceptors, support, expectations, transition programs. 


\section{BACKGROUND}

The transition from student nurse to graduate nurse contains two aspects; the transition process and preceptor support. The transition process is where graduate nurses are expected to grow to become competent Registered Nurses, developing their professional identity (Vittrup \& Davey, 2010). Patricia Benner highlights the stages of transition for the student nurse, however she cautions following the rigidity of structural levels when attempting to comprehend a nurses' level of competence (Gardner, 2012). Whilst graduate nurses undergo a transition phase as they move through novice to expert stages, it is not a linear or predictable process. Nevertheless, Benner's work holds significance for understanding the transition of the graduate nurse, as graduates are often intrinsically governed by organisational policy and procedure in order to compensate for lack of experience (Gardner, 2012). As the graduate obtains experience, their practice is influenced by various experiences, highlighting the notion that "nursing practice can be learnt, it cannot be taught" (Gardner, 2012, p. 340).

Internationally, there has been an issue identified with the transition process as students move from a theory-based program to the clinical area, known as the theory practice gap (Hatlevik, 2012). In 1984, nursing education in Australia transferred to the tertiary sector (Levett-Jones \& Fitzgerald, 2005). This changeover led to the perception that graduate nurses lacked clinical preparedness, stimulating a response and growth of transition programs (Levett-Jones \& Fitzgerald, 2005).

The aim of the transition program is to help the graduate “...learn the routines and procedures of the health care service, enhance confidence and competence, and facilitate professionalization and job satisfaction" (Happell \& Gough, 2007, p. 127). Internationally, elements such as mentorship, education and orientation remain integral to the program (Rush et al., 2013). In Australia there is a lack of nationally approved transition programs and 
consistency in specific program details (Missen et al., 2014: Levett-Jones \& Fitzgerald, 2005). Furthermore, Henderson et al. (2015) identify that while transition programs may have the 'best intentions' for graduate nurses, successful provision of graduate support is not always achieved. Support for the graduate nurse is essential as it promotes confidence and job satisfaction, with a direct link to potential adverse patient outcomes if not adequately provided (Gardiner \& Sheen, 2016). Graduate nurse transition programs use a more senior nurse to work with the graduate in a position of leadership and support, known as the preceptor.

The preceptor is a source of knowledge and support for the graduate nurse during their transition through the first year of practice (Carlson et al., 2009). Tracey and McGowan (2015) in their UK qualitative exploratory study of eight preceptors identified that effective preceptorship has a direct influence on graduate performance and the quality of patient care. Qualitative research by Shinners and Franqueiro (2015) in the US explored graduate nurse experiences of preceptors. The research highlighted five distinct areas of preceptor competence that graduate nurses believe to be important: a source of feedback, a teaching tool with adequate exposure to education opportunities, a role model on how to act, a facilitator to guide the graduate through the process and a clinical leader to enhance the graduates' critical thinking ability alongside their clinical skills. Australian research by Henderson et al. (2015) support this stance, adding that preceptors were a central component to the development of the graduate nurse. While the relationship and level of support between graduate and preceptor may change over time the preceptor provided an element of support which graduates felt was not attainable from others in the nursing team (Henderson et al., 2015).

Research exploring the preceptor experience in Lebanon identified that the preceptor considers the graduate nurse a novice requiring constant guidance and lacking independence 
(Kantar, 2012). Although nursing graduates eagerly enter the profession, they often lack the expected level of confidence required in interprofessional collaboration, impacting the provision of nursing care (Pfaff et al., 2014). The transition of the graduate nurse has been explored in depth, however there is little research exploring the preceptor's experience (Valizadeh et al., 2016). Additionally, there is a lack of understanding in how a preceptor's experiences, expectations and personal characteristics impact on the graduate nurse (Lalonde \& Hall, 2017). Understanding the role of the preceptor further will provide graduates with the opportunity to experience a higher level of support and job satisfaction (Palumbo et al., 2012). Transition into practice is a complex period where no single perspective can explain or demonstrate this multifaceted event. The current study sought to understand the preceptor experience to provide insight into the challenges and suggest recommendations for graduate transition programs.

\subsection{Purpose of the study}

The purpose of this study was to explore preceptor expectations of graduate nurse transition. The research questions for the study included:

1. What are the preceptors' expectations and previous experiences of preceptoring graduates?

2. To what extent do these expectations influence the preceptors' delivery of support?

\section{METHODS}

An interpretative phenomenological approach was undertaken to explore seven preceptors' expectations of graduate nurses. This methodology is a three step process involving the exploration of the lived experience, the meaning which it holds for participants and how these participants make sense of the event (Smith, 2011). Therefore, the phenomenological 
foundation describes the individual's experience to interpreting the construal of the participant (VanScoy \& Evanstad, 2015). In understanding how preceptors develop their own expectations, we can begin to comprehend how their experiences shape their support.

\section{Author's Perspectives}

This methodology requires the authors to reflect on their experience to assist with defining the themes (VanScoy \& Evenstad, 2015). The primary author has the 'lived' experience of being both a graduate nurse who undertook a graduate transition program and was a preceptor who now works as an academic. Reflecting on these experiences enabled an insider and researcher's view to derive richness and applicability to the data. The duality in the nurseresearcher role has been identified as a potential role conflict in qualitative interviews, pertaining in particular to research involving patients (Colbourne \& Sque, 2004). For the current study, incorporating a reflexive approach ensured a transparent approach to data collection, and removed the potential for role conflict between researcher and participant. The researcher demonstrated transparency by identifying her dual role as a nurse-researcher and acknowledged the importance of participant involvement in contributing to future practices (Bulpitt \& Martin, 2010).

\subsection{Sample}

The participant sample was seven RN's with experience in the nursing field responsible for assisting the graduate nurse in their transition into the clinical environment. Participants were unknown to the researcher and worked in a range of acute hospital areas from one public hospital. Purposive sampling was used, where participants were chosen based on their job, years of experience, and experience in the preceptor role. The aim was to include only preceptor nurses with three or more years' experience as a Registered Nurse. 


\subsection{Data Collection}

Face-to-face semi-structured interviews were conducted in a private room at the participants' workplace at a time of their convenience. The questions developed were based on the current literature which acknowledges the preceptor role and experience (Figure 1). Individual interviews provided the opportunity for discussion around the issues without fear or judgement from others (DiCicco-Bloom \& Crabtree, 2006). Interviews lasted approximately 30 minutes. This approach was based on the recommendation of Coyne et al. (2016) to keep the commitment of time required by participants relatively short to accommodate the clinical environment while not rushing the collection of data. Interviews were audio tape-recorded and transcribed verbatim. Data collection occurred over a four month time frame in 2016. A once-only interview was deemed appropriate as the study was concerned with past preceptoring experiences and as saturation was reached in one sitting, further interviews were not required. Additionally, nurses expressed their time restraint concerns and as the study was voluntary, any cooperation was time dependent. This met the ethical considerations. Data saturation was reached after six interviews and one further interview was conducted. Identification of data saturation was guided by the five dimensions of richness suggested by Ogden \& Cornwell (2010) which includes length of interview, descriptive characteristics, the personal response, the level of analysis in the participant response and the descriptions of behaviour.

\subsection{Data Analysis}

Thematic analysis using a six step process was used, allowing for the development of themes while supporting the researcher's own perspective (Attride-Stirling, 2001). Step one was to code the data by extracting specific segments of texts based on the research purpose of 
exploring expectations of transition. Step two involved identifying themes from the coded text and refining them further. This step involved the secondary researchers [EC and JN] reviewing the themes as "each theme has to be specific enough to pertain to one idea, but broad enough to find incarnations in various different text segments" (Attride-Stirling, 2001, p. 392). The third step involved constructing the thematic networks by grouping similar themes together; step four was the second stage of analysis; to explore the thematic networks followed by step five which involved summarizing the thematic networks. Finally step six involved interpreting the patterns identified, Attride-Stirling (2001) identify this as the most challenging process of data analysis.

\subsection{Ethical Considerations}

The study was reviewed and approved by the Human Research Ethics Committee (HREC/15/QPAH/529). Written informed consent was obtained from all participants, with all participants informed of the confidentiality and use of pseudonyms to protect privacy.

\section{Results}

The sample included a total of seven participants, with varying age [Range: 25 years-59 years], gender, level of education [Bachelor-Post grad certificate] and years of nursing experience [Range: 3-38 years] to provide a range of perspectives and insight into preceptorship.

The analysis resulted in three major themes: balancing the preceptor role, exploring past experiences reveals current expectations and developing relationships. These themes provided insight into the role of the preceptor. 


\subsection{Balancing the preceptor role}

Participants identified that their role as preceptor was a very important source of support for graduate nurses. The balance of helping and empowering rather than leading and expecting change was evident. Some participants further identified the importance of educating the graduate on how to balance work and life:

"I think talking about work/life balance is important in that - and that preceptor role should involve both." (Participant 5)

Participants believed their role should encompass the provision of personal and professional support. This suggests the transition from student to professional is one with multiple changes. One participant highlighted the importance of the level of environmental support, as education is nothing without the link to application (clinical practice). We are the link between the theory and application; "the support at the coalface, not just for education." (Participant 3)

This suggests that the 'coalface' or clinical environment is a setting which can be challenging to graduates. "It's that vicious circle; you come in and you want to get everything done, and you want to work like the people that have worked here for years, and then get all flustered when they can't do that." (Participant 4) While the clinical area might be focused on the need to complete clinical tasks for patients, it requires a balance between encouragement, support and tasks for the graduate's development as a qualified professional. Participants spoke about their aim to move the graduate from "learning rather than just task orientated". (Participant 3) 
The idea that participants can identify the importance of their role in graduate transition suggests a link to their own graduate experience. When questioned, some participants identified the link between their own experiences the support they offered:

“...they belittle you because of being a new nurse... so belittlement in front of patients has definitely happened to me in the past, and that's - I've always been, like, I do not want to be that kind of nurse, and I think that definitely makes a difference to my practise today in how I act with...graduate nurses. ” (Participant 5)

Another participant identified a significant link between the quality of a preceptor and a graduate's ability to function. She highlighted the importance of being open and transparent in teaching:

"I'd probably be more adamant to provide a good experience so that nobody had a terrible experience like me... because, you know, it can make or break you...I found it really traumatic because I didn't have a preceptor. Um, and so I've made it my mission to make sure everybody who comes into this ED knows that if they've got any questions about anything, they can come to me and ask at any point." (Participant 2)

Overall, participants demonstrated that support is imperative to the transition of graduate nurses. Preceptors were able to reflect on their own graduate development and the associated challenges they had. They identified their own experience and how this determined the type of support offered to the graduate. Support is not just dependent on the preceptor, but also on the nature of the environment. 


\subsection{Exploring past experiences reveals current expectations}

The expectations of preceptors were varied, but demonstrated a fine balance between support and dependence. Participants talked about their experience of working with graduates and explained that graduates who held expectations of transition influenced how the graduate developed in practice. In particular, participants identified that graduates seem to walk a fine line between requiring some support or being entirely dependent on their preceptor and expect this as part of transition:

"They expect... an awful lot of hand holding...-I think that they do need the help, but they also need to man up a bit and - and take responsibility”. (Participant 4)

Participants discussed the concept of graduates needing support but also identified that the transference of skills and knowledge to the new environment was an important skill to acquire:

“...solidification of their knowledge, their understanding, and just sort of the basic nursing principles and being able to look after patients". (Participant 1)

From the experience of one participant, expectations played a role in their own graduate experience:

“At uni they sort of don't really prepare you for what to expect”. (Participant 1)

Yet without a clear direction of what to expect, participants believe graduates develop their own personal picture of what practice should be, and end up getting caught up within this self-manifested vision and lose sight of the RN role: 
“...too busy getting wound up in the being idealistic... I think they have high expectations of themselves." (Participant 4)

The participants discussed several aspects of what they expected from the graduates when they worked with them. The expectations ranged from a good level of critical thinking; clinical skills or personality traits. However all participants focused on the delivery of safe, patient centred care from the graduate:

"I expect critical thinking. If you've-if you've done a three year degree for nursing and you come into an ED environment, I expect a level of critical thinking. ... as a grad I expect them to go, something's not right here, I'm going to escalate it now, rather than try to muddle my way through it ...I expect them to advocate for their patient, regardless of if they're an introvert or an extrovert." (Participant 2)

Despite patient advocacy being an important element for most participants, some identified personality traits as both an expectation and a predictor for success:

"You have to be flexible, adaptable, you have to be resilient, you know, because sometimes patients can be demanding, and full on. Good communication, friendly, honest, punctual.” (Participant 7)

Adaptation and flexibility to the graduate role was discussed in several interviews, with an expectation of self-awareness of skills and skill level. Some participants believed that an appreciation for the novice nature of the graduate role was important for practice. Once 
again, critical thinking combined with self-awareness was important for participants as they believed this also reflected the future practice of the graduate nurse:

"I expect people to be just... sympathetic towards being a new nurse and still very junior. ...I also, expect them to say if you're doing something wrong, because I think that's important. If you're not-if you carry on doing the same practise and it's terrible... you'll probably end up being a bad nurse because no-one's really told you otherwise." (Participant 5)

Whilst participants explained they had multiple professional and personal expectations of graduate nurses, the aspect of time for development was highlighted. Furthermore, expecting that graduates adapt to the new environment immediately is beyond expectations, comments from several participants highlighted needing time; 'you can't expect people to do everything within their first two weeks'. (Participant 1)

Personal skills such as flexibility, critical thinking and emotional intelligence were acknowledged as part of becoming a professional. Some participants were able to identify the challenges associated with graduate transition, including identification of multiple expectations. These participants identified the pressure graduates may feel, offering an example of their support:

“Look, just take a breath. You're going to have some days where you're just not sort of as proficient as some of the other nurses you're working with, and that will come with time." (Participant 1) 
The preceptors described being able to comprehend the associated expectations the graduate holds of their transition time and adjust their support accordingly. However, it seems that preceptors all retain differing expectations themselves, with some expecting respect for the graduate role, independence, critical thinking and the ability to self-reflect.

\subsection{Developing relationships}

Personal characteristics of the graduate nurse were discussed by all participants in relation to the connection between the preceptor and graduate. In particular, age of the graduate nurse was an aspect which seemed to influence the relationship. One nurse identified the positive aspect of the older graduate (life experience) but also identified the younger graduates' ability to adapt to the new environment:

“...age always... having that life experience is always helpful....but I see youth as sort of an ability to be really - you get up ready to learn, be able to adapt and change as things go on." (Participant 1)

The development from student to professional included a lifestyle adaptation. A certain level of maturity with the commencement of the role is expected. Participants discussed this point referring to the personal maturity of learning how to cope with shift work as well as the clinical challenges:

"You really learn when you're a graduate that you can't party 'til 3 am and then go to work. I mean, that just-like, in this environment, it just has to stop, and that's something, well, I don't know, as a-a graduate from a-like, a young graduate, those sort of lifestyle changes you have to be... able to change, I think, and 
compromise for your profession, like, 'cause you're now a professional." (Participant 5)

Building on the concept of relationships, participants felt that the younger graduate nurses demonstrate more flexibility in adapting to a new environment compared to the graduate with life experience who may struggle with the change:

“..I found probably the first six weeks were - I found probably her [the graduate] hardest. Um, she excelled, she did exceptionally, but it's just making that transition from being a student who is always under direction to having your own patient load, to being responsible for that patient, and yeah, it's a big step for a student, and, um, the nurse with 20 years' experience that I'm currently precepting, ah, I found her first two weeks were probably quite hard, and she's admitted that...” (Participant 2)

One younger participant believed that being a similar age to the graduate nurse was an advantage for her as she could develop a connection. This younger participant discussed the different qualities that age presented:

"I'm someone, as opposed to, like, a-a person nursing for 50 years, I might be more approachable as a person to talk to about, um, work/life balance...whereas they can probably benefit from other qualities of someone that's been nursing for 50 years, like, knowledge, um, also reflecting on older practises versus new practises." (Participant 5) 
While graduate youth was seen as an ability to adapt faster to new environments and valued for its flexibility, other participants valued older graduates for their life experience and maturity:

“...girls with a bit of experience behind them and a bit of common sense.... Age and experience.... I think it gives people confidence. So if they're going to give somebody a medication, they're more aware to go back and check that person again, ... same as if you give your child medication, you'll check your child... Maturity." (Participant 4)

Another participant identified that the age of a graduate determines how they respond and treat patients:

"I think the older graduates are probably a little bit more mature, able to speak to people. Some of the younger graduates are not good at talking to people." (Participant 7)

Yet another participant highlighted that age should not be a determinant of patient care. Age does not outweigh the ability to critically think about a situation, no matter the individual, the patient always takes priority:

“...cause even as experienced nurses, we don't always know what's wrong with our patient, but if your gut feeling says speak up, you have to speak up. It doesn't matter if you've been doing this job for 30 years or if you're a grad straight out of uni, you speak up." (Participant 2) 
What was interesting about this topic was nurses who believed older graduates made better nurses, were older themselves. A final aspect of personal characteristics was personality. One participant admitted that the personality of a graduate and their attitude towards learning directly influenced her level of teaching:

“...if I get a keen enthusiastic nurse here, I'll support her all the way, you know. But if someone's a bit distant and disinterested and not really communicating, to be honest, I don't even want to make the effort any more. I don't." (Participant 7)

Despite the personality of a graduate, participants discussed how no two graduates are the same. They spoke of being perceptive of the graduates' ability to ask for help, which directed their level of support:

“...graduates differ. They differ as much as the days differ. You've got some that will go, "Yep, yep," and go and do what they need to do, or, say, "I need a hand," and then you've got others that step back and won't do a thing, and then you've got others that are just-get themselves in a flap. You've got to read each student individually..." (Participant 4)

The level of support offered to graduates was influenced by the graduates' personal qualities/characteristics. The graduates' enthusiasm to learn seemed to earn them more support from the preceptor. The participants in this study appeared to favour graduates who were closer to their own age. 


\section{Discussion}

This study explored preceptor expectations regarding the graduate nurse, illustrating the complexities within this transition period. Three themes emerged from the data; balancing the preceptor role, exploring past experiences reveals current expectations and developing relationships.

Participants in the current study reflected on their role as a preceptor, discussing how their own graduate transition shaped the way they developed as a preceptor. The majority believed a negative experience as a graduate themselves made for a better preceptor, as this led them to work harder to provide genuine support and guidance to the graduate. However, Gardiner and Sheen (2016) highlighted that the preceptor is one component in the complex clinical area; graduates require an environment of support that includes appropriate staffing skill mix, supervision and the presence of clinical educators. Although Lea and Cruickshank (2015) identified in their Australian study that graduates are the best indicator of the level and types of support they require, however their ability to seek support depends their ability to ask and confidence in doing so.

In the current study the participants described their role as preceptors and how they provided support to the graduate in relation to their own experience as a graduate. This is often the process of teaching; using our own experiences to teach others (Benner, 1984). As Spurr et al. (2010) argue, there is no one method to teaching, it is often driven and influenced by the teacher's philosophical beliefs. However it is assumed that the competent clinician will also be a good preceptor, although literature identifies that effective preceptors must demonstrate personal and professional qualities for graduates to feel supported (Shinners \& Franqueiro, 2015). The current study demonstrated that preceptor experience plays a major role in 
determining the quality of the preceptor while education and support for this role is also required to ensure preceptors can meet the support needs of the graduate (Palumbo et al., 2012).

The preceptors discussed the importance of the balance of support in line with their own expectations. The current study identified that preceptors expect a certain level of independence, with elements of critical thinking and self-reflection. However preceptors believe that graduates expect an extensive amount of support, to the point where dependence on the preceptor may occur. A qualitative study of 10 graduate nurses in Ireland by Kumaran \& Carney (2014) identified that graduates believed preceptor expectations were significantly increased as a graduate compared to their time as a student nurse. In line with the current study, this suggests that not only are graduate and preceptor expectations mismatched, preceptor expectations of clinical work are critical thinking are higher than what graduates are capable of (Kumaran \& Carney, 2014). This could explain why preceptors believe that graduate nurses are dependent on their support, in an attempt to meet the preceptor expectations.

Expectations of the preceptors in relation to graduate nurse performance were varied. This is supported by Clark and Holmes (2007), who revealed that graduates and preceptors have different expectations within the transition time, and ward staff themselves were unable to agree on what should be expected from the new nurses. Preceptors in the current study believed that graduates do not have the ability to perform without guidance and subsequently lacked confidence in the ability of graduates to provide effective patient care. Goh \& Watt (2003) in their Australian study of five graduate nurses also identified that expectations in line with confidence are determinants of graduate development. Without clear expectations, support 
and feedback for graduates, poor patient care can result (Irwin et al., 2018). A recommendation would be to review current graduate support to ensure expectations placed on graduates do not hinder their development and provision of care.

The preceptors within the current study highlighted that graduates develop their own belief of what a nurse should encompass, and can become lost in their own self-derived view of nursing. Similarly, Christiansen (2008) in their qualitative study in Norway, identified that tension between the ideals of the nurse themselves and what is expected in reality is a concern. Although Cleary et al. (2013) who interviewed 17 graduates of a large university in Singapore, identified graduate nurses are disappointed with the profession as the reality of practice does not match their aspirations of patient care. This is an important element, as the experiences encountered by the graduate nurse can determine their career pathway (Cleary et al., 2013).

In the current research, each preceptor had developed their own expectations and associated methods of support. A correlation was found between the present study and the Canadian study conducted by Lalonde and McGillis Hall (2017), whereby preceptor traits were related to graduate nurse outcome. In their study of 41 preceptors and 44 graduate nurses, the preceptor who demonstrates openness, conscientiousness and a calm emotional stance all connected to negative graduate outcomes such as role ambiguity, job dissatisfaction and turnover intent. Particularly, it was suggested that conscientious preceptors may have higher expectations regarding graduate nurse performance (Lalonde \& McGillis Hall, 2017). The preceptors within the current study described similar traits such as openness and transparency in providing support. This suggests that preceptor qualities which are intended to support the graduate, may be hindering the development of the graduate nurse. 
Preceptors highlighted that graduates are often time and task focused. Kantar (2012), highlighted similar findings particularly motivation of tasks within the clinical unit. A reliance by graduate nurses on electronic devices to guide their assessment and care of patients reinforced the notion of task orientation and needing to learn to be a holistic nurse (Hartigan et al., 2010). According to the preceptors in the current study, graduates need to become more learning orientated rather than task orientated to develop as a nurse. According to Kantar (2012), the clinical situations graduate nurses encounter are learning situations, with $80 \%$ of preceptors identifying the need for significant coaching during this time and reliance on others for cues on patient care. In line with the current study this reliance demonstrates the lack of independence and inflexibility of the graduate in making independent clinical decisions.

Personal characteristics of the graduate nurse influence the support provided by the preceptor. The age of the graduate was important to the preceptor as this influenced the connection they developed with the graduate. Some believed that youth demonstrated an ability to be flexible to the environment, while others believed that the older graduate was able to utilise their life experience and connect more with patients. However as demonstrated by Beecroft et al. (2008) in their US study spanning 7 years, the older graduate ( $>30$ years old) is more likely to leave their job if the ward allocated does not align with their fixed career goals, a quality which the study indicates is only applicable to older nursing graduates. This demonstrates the potential for preceptor support to be age dependent, and the complexity in supporting varying ages of nursing graduates. Additionally, graduate enthusiasm for their new role was met with high levels of support from the preceptor, as the graduate displayed their willingness to learn. However, the Australian study conducted by Cowin \& Johnson (2015) identified graduate 
nursing qualities such as knowledge and respect for the profession declined in the graduate year. Qualities required in the transition time are not retained after the graduate year, highlighting the need for preceptor education and support to ensure longer term graduate transition.

The relationship between preceptor and graduate is a key aspect of how the preceptor then provides support. This relationship seems to be the connection between the preceptor and graduate which relates to how they are able to share information. Research completed by Robitaille (2013) explains that a preceptor may demonstrate excellent clinical qualities of preceptorship but lack a dynamic connection with the graduate, leaving the graduate in a void of support. Additionally, Giallonardo et al. (2010) in their Canadian study identified that when graduate nurses are paired with preceptors who demonstrate an authentic leadership style, job satisfaction and engagement is heightened. This suggests that the relationship between graduate and preceptor extends beyond professional realms and requires a personal connection for both preceptor and graduate.

It is evident that the graduate-preceptor relationship should also encompass the environment itself. In a Canadian-based mixed methods study of 245 nursing graduates by Rush et al. (2014), they acknowledged that 60 per cent of graduates identified a need for significant provision of support in regards to people and environmental support in their first few months, demonstrating sense of vulnerability in this early stage of transition. Multiple authors identify the value of an empowering environment in the nursing workforce and how this influences graduate development (DeVivo et al., 2013; Laschinger \& Smith, 2013; Wing et al., 2015). Providing an environment of support and empowerment will enable to the graduate to understand the required level of clinical practice and feel confident in asking for support and 
thus promoting the retention of graduates for the future nursing workforce (Cheeks \& Dunn, 2010; Wing et al., 2015).

\subsection{Limitations}

This study has several limitations particularly as the data was collected at one point in time, it is unclear if preceptors had different expectations and opinions of the graduates at different intervals during the year. Participants were nurses who volunteered their time, potentially biased to those with a positive attitude to students. Follow up interviews may have allowed participants to clarify interpretations from the interviews, reducing potential bias and increasing strength to the data collection (Fusch \& Ness, 2015). Although the participant number was small, the intent of this study was to produce credible findings, and it is feasible that nurses in similar settings will experience comparable issues (Sandelowski, 1995). Extending the study to include nurses from other health care facilities would provide further insight into the expectations of preceptors in graduate nurse transition. Despite the limitations, data collected provided vital insight into the preceptor role.

\subsection{Recommendations for practice}

Addressing the components of support, expectations, relationship building and connection between graduate and preceptor through structured workshops may be beneficial to preceptors. Training preceptors how to connect and communicate with the graduate nurse may assist in strengthening the relationship. Additionally, incorporating both the graduate and preceptor into relationship building workshops would enhance the supportive nature of this relationship. Organisations should identify that an ideal learning environment needs to incorporate theoretical and practical elements which should complement each other for effective graduate nurse support (Kalayi et al., 2013). 


\section{Conclusion}

Developing a strong preceptor graduate relationship was identified as a key aspect for supporting the graduate. This research found that while preceptors understand the support required in the graduate year of transition, the provision of support was influenced by personal preceptor experience and graduate qualities. This study provided insight and understanding into the concept of balancing the role of support to enhance the graduate's development. While some organisations currently provide education to graduates, the further development of structured education, relationship and communication programs for graduate nurse and preceptors would be useful to improve future transition programs. 


\section{References}

Attride-Stirling, J., 2001. Thematic networks: an analytic tool for qualitative research. Qualitative Research, 1(3), 385-405.

Beecroft, P. C., Dorey, F., \& Wenten, M., 2008. Turnover intention in new graduate nurses: A multivariate analysis. Journal of Advanced Nursing, 62(1), 41-52.

Benner, P., 1984. From Novice to Expert: Excellence and Power in Clinical Nursing. Addison Wesley, California.

Bulpitt, H., \& Martin, P. J., 2010. Who am I and what am I doing? becoming a qualitative research interviewer. Nurse Researcher, 17(3), 7-16.

Carlson, E., Wann-Hansson, C., \& Pilhammar, E., 2009. Teaching during clinical practice: Strategies and techniques used by preceptors in nursing education. Nurse Education Today, 29(5), 522-526.

Cheeks, P., \& Dunn, P. S., 2010. A New-Graduate Program: Empowering the Novice Nurse. Journal for Nurses in Staff Development (JNSD), 26(5), 223-227.

Clark, T., \& Holmes, S., 2007. Fit for practice? An exploration of the development of newly qualified nurses using focus groups. International Journal of Nursing Studies, 44(7), $1210-1220$.

Cleary, M., Horsfall, J., Jackson, D., Muthulakshmi, P., \& Hunt, G. E., 2013. Recent graduate nurse views of nursing, work and leadership. Journal of Clinical Nursing, 22(19-20), 2904-2911.

Coyne, E., Grafton, E., \& Reid, A., 2016. Strategies to successfully recruit and engage clinical nurses as participants in qualitative clinical research. Contemporary Nurse, 52(6), 669676.

Colbourne, L., \& Sque, M., 2004. Split personalities: Role conflict between the nurse and the nurse researcher. Journal of Research in Nursing, 9(4), 297-304. 
Cowin, L. S., \& Johnson, M., 2015. From student to graduate: Longitudinal changes in the qualities of nurses. Journal of Advanced Nursing, 71(12), 2911-2922.

DeVivo, D., Griffin, M. T. Q., Donahue, M., \& Fitzpatrick, J. J., 2013. Perceptions of Empowerment Among ED Nurses. Journal of Emergency Nursing, 39(6), 529-533.

DiCicco - Bloom, B., \& Crabtree, B. F., 2006. The qualitative research interview. Medical Education, 40(4), 314-321.

Fusch, P. I., \& Ness, L. R., 2015. Are we there yet? Data saturation in qualitative research. Qualitative Report, 20(9), 1408-1416.

Gardiner, I., \& Sheen, J., 2016. Graduate nurse experiences of support: A review. Nurse Education Today, 40, 7-12.

Gardner, L., 2012. From Novice to Expert: Benner's legacy for nurse education. Nurse Education Today, 32(4), 339-340.

Giallonardo, L. M., Wong, C. A., \& Iwasiw, C. L., 2010. Authentic leadership of preceptors: Predictor of new graduate nurses' work engagement and job satisfaction. Journal of Nursing Management, 18(8), 993-1003.

Hartigan, I., Murphy, S., Flynn, A. V., \& Walshe, N., 2010. Acute nursing episodes which challenge graduate's competence: Perceptions of registered nurses. Nurse Education in Practice, 10(5), 291-297.

Hatlevik, I.K.R. 2012. The theory-practice relationship: reflective skills and theoretical knowledge as key factors in bridging the gap between theory and practice in initial nursing education. Journal of Advanced Nursing, 68(4),868-877.

Happell, B., \& Gough, K., 2007. Employment Through Residency Programs: A Strategy to Address the Workforce Crisis in Psychiatric Nursing. Archives of Psychiatric Nursing, 21(3), 126-131. 
Henderson, A., Ossenberg, C., \& Tyler, S., 2015. 'what matters to graduates': An evaluation of a structured clinical support program for newly graduated nurses. Nurse Education in Practice, 15(3), 225-231.

Irwin, C., Bliss, J., \& Poole, K., 2018. Does preceptorship improve confidence and competence in newly qualified nurses: A systematic literture review. Nurse Education Today, 60, 35-46.

Kalayi, G., Madhavanprabhakaran, \& Akintola, A. A., 2013. Preceptorship: Bridging the Theory Practice Gap and Enhancing Transition of New Graduates. International Journal of Nursing Care, 1(1), 25-29.

Kantar, L. D., 2012. Clinical Practice of New Nurse Graduates in Lebanon: Challenges and Perspectives Through the Eyes of Preceptors. The Journal of Continuing Education in Nursing, 43(11), 518-528.

Kumaran, S., \& Carney, M., 2014. Role transition from student nurse to staff nurse: Facilitating the transition period. Nurse Education in Practice, 14(6), 605-611.

Lalonde, M., \& McGillis Hall, L., 2017. Preceptor characteristics and the socialization outcomes of new graduate nurses during a preceptorship programme. Nursing Open, 4(1), 24-31.

Laschinger, H. K. S., \& Smith, L. M., 2013. The Influence of Authentic Leadership and Empowerment on New-Graduate Nurses' Perceptions of Interprofessional Collaboration. JONA: The Journal of Nursing Administration, 43(1), 24-29.

Lea, J., \& Cruickshank, M., 2015. Supporting new graduate nurses making the transition to rural nursing practice: views from experienced rural nurses. Journal of Clinical Nursing, 24(19-20), 2826-2834.

Levett-Jones, T., \& Fitzgerald, M., 2005. A review of graduate nurse transition programs in Australia. Australian Journal of Advanced Nursing, 23(2), 40-45. 
Missen, K., McKenna, L., \& Beauchamp, A., 2014. Graduate Nurse Program Coordinators' perspectives on graduate nurse programs in Victoria, Australia: A descriptive qualitative approach. Collegian, 23(2), 201-208.

Ogden, J., \& Cornwell, D., 2010. The role of topic, interviewee and question in predicting rich interview data in the field of health research. Sociology of Health \& Illness, 32(7), 1059-1071.

Palumbo, M. V., Rambur, B. A., \& Boyer, S. A., 2012. Education and employment characteristics of nurse preceptors. The Journal of Continuing Education in Nursing, 43(10), 472-480.

Pfaff, K., Baxter, P., Jack, S., \& Ploeg, J., 2014. Exploring new graduate nurse confidence in interprofessional collaboration: A mixed methods study. International Journal of Nursing Studies, 51(8), 1142-1152.

Robitaille, P., 2013. In Focus: Preceptor-based orientation programs for new nurse graduates. Association of Operating Room Nurses. AORN Journal, 98(5), C7-C8.

Rush, K. L., Adamack, M., Gordon, J., \& Janke, R., 2014. New graduate nurse transition programs: Relationships with bullying and access to support. Contemporary Nurse, 48(2), 219-228.

Rush, K. L., Adamack, M., Gordon, J., Lilly, M., \& Janke, R., 2013. Best practices of formal new graduate nurse transition programs: An integrative review. International Journal of Nursing Studies, 50(3), 345-356.

Sandelowski, M., 1995. Sample size in qualitative research. Research in Nursing \& Health, $18(2), 179-183$. 
Shinners, J. S., \& Franqueiro, T., 2015. Preceptor Skills and Characteristics: Considerations for Preceptor Education. The Journal of Continuing Education in Nursing, 46(5), 233236.

Smith, J. A., 2011. Evaluating the contribution of interpretative phenomenological analysis. Health Psychology Review, 5(1), 9-27.

Spurr, S., Bally, J., \& Ferguson, L., 2010. A framework for clinical teaching: A passioncentered philosophy. Nurse Education in Practice, 10(6), 349-354.

Tracey, J. M., \& McGowan, I. W., 2015. Preceptors' views on their role in supporting newly qualified nurses. British Journal of Nursing, 24(20), 998-1001.

Valizadeh, S., Borimnejad, L., Rahmani, A., Gholizadeh, L., \& Shahbazi, S., 2016. Challenges of the preceptors working with new nurses: A phenomenological research study. Nurse Education Today, 44, 92-97.

VanScoy, A., \& Evenstad, S. B., 2015. Interpretative phenomenological analysis for LIS research. Journal of Documentation, 71(2), 338-357.

Vittrup, A. C., \& Davey, A. (2010). Problem based learning - 'Bringing everything together' - A strategy for Graduate Nurse Programs. Nurse Education in Practice, 10(2), 88-95.

Wing, T., Regan, S., \& Spence Laschinger, H. K., 2015. The influence of empowerment and incivility on the mental health of new graduate nurses. Journal of Nursing Management, 23(5), 632-643. 